ORIGINAL ARTICLE

\title{
Attitudes of preclinical medical students towards caring for chronically ill and dying patients: does palliative care teaching make a difference?
}

\author{
M Lloyd-Williams, N Dogra
}

Postgrad Med J 2004;80:31-34. doi: 10.1136/pgmj.2003.009571

Introduction: Students entering medical school today will encounter an ageing population and a higher incidence of diseases affecting the elderly-for example, chronic respiratory and cardiac disease and malignancy.

Purpose: This study was carried out to determine the attitudes of preclinical medical students towards the care of patients for whom a cure is not possible.

See end of article for authors' affiliations

Correspondence to: Professor M Lloyd-Williams, Department of Primary Care, University of Liverpool Medical School Brownlow Hill, Liverpool, L69 3GB, UK. mlw@liv.ac.uk

Submitted 1 May 2003 Accepted 2 June 2003
Methods: All students were invited to complete a 23 item questionnaire prior to initial teaching and again following the second teaching session in palliative care.

Results: Overall, 149 of the 186 students (80\%) completed the pre-teaching questionnaire 159 males and 90 females; median age 20 years, range 19-27 years), and 66 students (35\%) completed the postteaching questionnaire. Attitudes towards chronically ill and dying patients were generally positive. It was found that increasing age was associated with a more positive view of caring for patients with chronic or terminal illness, a more positive view of listening to patients reminisce, and a more positive view of patients dying at home $(p=0.014)$. The only notable result was that after palliative care teaching students had a significantly more positive view of hospices.

Conclusion: Caring for patients at the end of life can be one of the most rewarding aspects of being a doctor. This study suggests that the majority of medical students have a positive attitude towards patients with chronic incurable illness, and the trend for encouraging older students to enter medicine may be an influencing factor.
M ost students who want to become doctors often cite their reason for entering medicine as wanting to cure patients. However, the reality of medicine is that the majority of doctors will spend much of their time caring for patients with chronic progressive illness for whom no cure is possible. Students entering medical school today will encounter an ageing population and an increased incidence of diseases affecting the elderly-for example, chronic respiratory and cardiac disease, cerebral degeneration, and malignancy. Over $90 \%$ of hospital beds are occupied by patients with chronic disease or illness; for these patients, the control of symptoms and supportive care or palliative care is important.

In light of the report by the General Medical Council Tomorrow's Doctors, the undergraduate medical curriculum has tried to take these factors into account by placing increased emphasis on sociological and community aspects of medicine, with students spending more time working in primary care teams, community based health initiatives, and community hospitals. There is emphasis on students gaining clinical exposure during the preclinical years and building on that during subsequent clinical attachments.

It is known that palliative care is an area that many medical students find difficult. ${ }^{1}$ Although teaching in palliative care is not given as much time as other specialties, there has been an increase in teaching in this area over the last 15 years. ${ }^{2-7}$ Previous studies have looked at the attitudes of medical students prior to palliative care teaching. In a study looking at fear of death, medical students expressed more unease at the thought of caring for dying patients than did nursing students or practising physicians. The study also found that students who were intolerant of clinical uncertainty gave higher scores on a thanatophobia (fear of death) scale. $^{8}$ Although nurses are widely thought to be more comfortable in communicating with patients who are dying, both medical and nursing students find difficulty with the concept of talking about death with patients and with general interaction with such patients. ${ }^{9}$

This study was carried out to determine the attitudes of preclinical medical students towards the care of patients for whom a cure is not possible, before and immediately after formal teaching on the subject.

\section{METHODS}

The medical school where this study was carried out has developed a progressive integrated curriculum and accepts medical students from access courses. It also recently introduced a four year course for graduates in biological sciences.

All students were invited to complete a 23 item questionnaire. A number of statements on a 10 point Likert scale were listed in a random order with both positively and negatively worded statements. Students were asked to indicate the strength of their agreement or disagreement immediately before the first teaching session and at the end of their formal teaching in palliative care. The statements addressed the issues of attitudes towards cure versus care of patients, end of life care, beliefs regarding pain and the use of opiates, patients' autonomy, and the students' views on communication and living wills. The questionnaire was compiled with input from palliative care, psychiatry, and medical education disciplines and was piloted initially on 10 students for face validity. Students were asked to give their age and sex, and all data were collected anonymously.

The teaching was six hours over two sessions a week apart and consisted of two one hour lectures with opportunity for 
interaction and a variety of teaching media, for example a video of a terminally ill patient talking about their illness. In addition, four hours of small group work was available for students to explore their attitudes towards caring for patients who are chronically ill and their own attitudes towards death. A number of case histories were available to facilitate small group discussion. This teaching is given in the second year of the preclinical course and the first year of the accelerated four year course. The formal lectures were given by a consultant in palliative medicine, and small groups were facilitated by a palliative care doctor or clinical nurse specialist. These two sessions form part of the "human diversity" module and are the first formal teaching students receive on the care of patients with chronic illness and on palliative care.

The objectives for the sessions were stated as:

- Identify the major areas of impact on the patients and family when a life threatening disease is diagnosed.

- Describe the various healthcare agencies and their roles in supporting patients.

- Compare and contrast palliative care and mainstream medicine.

- Consider how psychological, social, spiritual, and cultural factors may affect the dying patient.

\section{Analysis}

As the age and questionnaire items were mostly skewed, non-parametric tests were used for the analysis. To test whether there was a difference in the way males and females answered the questionnaire, the Mann-Whitney U test was used. To test for associations between age and how the questions were answered, Spearman's rank correlation coefficient was used.

\section{RESULTS}

In total, 149 of the 186 students $(80 \%)$ completed the preteaching questionnaire ( 59 males and 90 females; median age 20 years; range 19-27 years), and 66 students (35\%) completed the post-teaching questionnaire.

Prior to teaching, both male and female students exhibited positive attitudes towards spending time with and communicating with patients (median score of 10, indicating strong agreement) and believed that patients had a right to be given information about their illness and that such information should not be withheld by relatives (median score of 9). Students also had positive views on the inclusion of children when an adult is dying. The median score for "most cancer patients have pain that cannot effectively be relieved" was 5 . It must be emphasised that students at this stage would have received very little teaching in the use of drugs and pharmacology. Questions were grouped into broad areas, and the pre-teaching questionnaire showed that female students had significantly more positive views on spending time with patients $(p=0.032)$ and communicating with children about an adult's illness $(\mathrm{p}=0.035)$ than did the male students questioned.

Female students were significantly more likely to believe that most cancer patients had pain that could not be adequately relieved than were male students $(p=0.018)$.

When comparing age with attitudes, it was found that increasing age was associated with a more positive view of caring for patients with a chronic life threatening or terminal illness $(p=0.001), a$ more positive view of listening to patients reminisce $(p=0.009)$, and a more positive view of patients dying at home $(\mathrm{p}=0.014)$ (table 1$)$.

\section{Comparison of the questionnaire results before and after teaching}

Far fewer people answered the second questionnaire (66 people answered the second questionnaire compared with 149 people who answered the first). To check for confounding factors, the age and sex of the responders were compared between the two questionnaires, but there were no significant differences: $40 \%$ (60 out of 149) of responders to the first questionnaire were male, compared with 52\% (34 out of 66) of responders to the second questionnaire. There was no evidence to suggest a difference between the median ages of the people who answered the two questionnaires. Increasing age was associated with a more positive view of caring for patients during the last weeks of their lives $(p=0.016)$ after palliative care teaching.

When comparing the two questionnaires, the only significant difference found between the response before teaching and the response after teaching was for the statement regarding hospices: after palliative care teaching the students had a significantly more positive view of hospices $(p=0.004)$ (table 2$)$.

\section{DISCUSSION}

Caring for patients at the end of life can be one of the most rewarding aspects of being a doctor. This study of preclinical medical students suggests that the majority have a positive attitude towards patients with chronic incurable illness and towards those patients dying of cancer before any formal teaching on this subject. Students placed value on talking with and spending time with patients and perceived that this can be rewarding. Medical students also believed in living wills being legally binding, supporting a previous finding in a study from the USA. ${ }^{10}$

Female students had significantly more positive views on spending time with patients and communicating with children than did the male students questioned. However, female students were significantly more likely than male students to believe that most cancer patients had pain that could not be adequately relieved. When comparing age with attitudes, it was found that increasing age was significantly associated with a more positive view of being able to care for as opposed to curing patients and a more positive view of listening to patients. Older students also had a more positive view of patients dying at home.

The study demonstrated little difference in attitudes after completion of palliative care teaching, with the exception of a significantly more positive view of hospices. Although the initial completion rate of $80 \%$ was good, the post-teaching response rate was poor at 35\%; before teaching all questionnaires were handed out at the beginning of the lecture, whereas post-teaching questionnaires were handed out by individual tutors at the end of the small group work, and these tutors may not have emphasised the importance of completion. Caution must therefore be used in interpreting the significance or otherwise of the post-teaching data. This study looked at the attitudes of preclinical students; there is evidence that attitudes change and become more positive during clinical training. The attitudes of medical students change over time with different teaching and experiential exposures. ${ }^{11-15}$ A limitation of our study is that it looked at only one aspect of teaching and did not measure any changes in attitudes over time.

Previous studies have aimed to evaluate whether clinical palliative care teaching has any effect on attitudes towards patients who are chronically ill or who have advanced cancer. In a study of students who had undertaken additional teaching compared to those who had received the initial second year (didactic) teaching, there was no significant difference in attitudes. ${ }^{16}$ However, a study to determine the 
Table 1 Spearman's rank correlation coefficient to test for an association between age and palliative care views, calculated for individual questions (significant values in bold)

\begin{tabular}{|c|c|c|}
\hline & $\begin{array}{l}\text { Spearman's rank correlation } \\
\text { coefficient }\end{array}$ & $p$ Value \\
\hline Not curing patients is a failure for doctors & -0.271 & 0.001 \\
\hline Talking to patients is an important part of a doctor's role & 0.021 & 0.794 \\
\hline I enjoy listening to patients reminisce & -0.214 & 0.009 \\
\hline $\begin{array}{l}\text { I would like to work in a specialty where my patients are } \\
\text { likely to be cured }\end{array}$ & 0.020 & 0.804 \\
\hline $\begin{array}{l}\text { I would like to work in a specialty where I can really get to know } \\
\text { my patients }\end{array}$ & -0.071 & 0.386 \\
\hline $\begin{array}{l}\text { If a patient has an illness, it is the doctor's job to give them } \\
\text { the facts }\end{array}$ & 0.089 & 0.277 \\
\hline $\begin{array}{l}\text { If a patient gets upset in the ward, the doctor should spend } \\
\text { time talking to them }\end{array}$ & -0.115 & 0.159 \\
\hline If a patient gets upset, they should not bother the doctor & 0.071 & 0.387 \\
\hline Living wills should be legálly binding & 0.045 & 0.580 \\
\hline I believe that morphine is addictive in cancer patients & 0.042 & 0.611 \\
\hline Hospices are only for patients who are dying & -0.067 & 0.412 \\
\hline Most cancer patients have pain that cannot effectively be relieved & -0.102 & 0.215 \\
\hline Morphine should be used only in the last weeks of life & 0.006 & 0.945 \\
\hline $\begin{array}{l}\text { Very little can be done to help cancer patients during the } \\
\text { last weeks of life }\end{array}$ & -0.158 & 0.053 \\
\hline $\begin{array}{l}\text { Patients should be told the truth if they ask whether they } \\
\text { are going to die }\end{array}$ & 0.067 & 0.415 \\
\hline It is better if children do not attend funerals & -0.035 & 0.672 \\
\hline We do not need to talk to children about death and dying & -0.119 & 0.146 \\
\hline Children have no understanding of death & -0.141 & 0.084 \\
\hline $\begin{array}{l}\text { Relatives have a right to insist that doctors do not tell a } \\
\text { patient he or she has cancer }\end{array}$ & 0.133 & 0.104 \\
\hline $\begin{array}{l}\text { Chaplains and religious leaders have an important role in } \\
\text { helping non-religious terminally ill patients }\end{array}$ & -0.123 & 0.133 \\
\hline Patients should be allowed to die at home if that is their wish & 0.199 & 0.014 \\
\hline Hospices can be positive places & 0.084 & 0.303 \\
\hline $\begin{array}{l}\text { Caring for terminally ill patients as doctors can be a } \\
\text { rewarding job }\end{array}$ & 0.122 & 0.137 \\
\hline
\end{tabular}

Table 2 A comparison of responses before and after teaching (significant values in bold)

\begin{tabular}{|c|c|c|c|}
\hline & $\begin{array}{l}\text { Before teaching } \\
(n=149)\end{array}$ & $\begin{array}{l}\text { After teaching } \\
(\mathrm{n}=66)\end{array}$ & p Value \\
\hline Age & 20 & 20 & 0.061 \\
\hline Not curing patients is a failure for doctors & 2.0 & 2.0 & 0.167 \\
\hline Talking to patients is an important part of a doctor's role & 10.0 & 10.0 & 0.172 \\
\hline I enjoy listening to patients reminisce & 7.0 & 7.0 & 0.550 \\
\hline $\begin{array}{l}\text { I would like to work in a specialty where my patients are likely } \\
\text { to be cured }\end{array}$ & 7.0 & 6.0 & 0.396 \\
\hline $\begin{array}{l}\text { I would like to work in a specialty where I can really get to know } \\
\text { my patients }\end{array}$ & 9.0 & 8.0 & 0.712 \\
\hline If a patient has an illness, it is the doctor's job to give them the facts & 9.0 & 9.0 & 0.213 \\
\hline $\begin{array}{l}\text { If a patient gets upset in the ward, the doctor should spend time } \\
\text { talking to them }\end{array}$ & 8.0 & 9.0 & 0.185 \\
\hline If a patient gets upset, they should not bother the doctor & 2.0 & 2.0 & 0.687 \\
\hline Living wills should be legally binding & 7.0 & 6.0 & 0.066 \\
\hline I believe that morphine is addictive in cancer patients & 5.0 & 6.0 & 0.454 \\
\hline Hospices are only for patients who are dying & 4.0 & 3.0 & 0.004 \\
\hline Most cancer patients have pain that cannot effectively be relieved & 5.0 & 4.0 & 0.552 \\
\hline Morphine should be used only in the last weeks of life & 4.0 & 3.0 & 0.464 \\
\hline $\begin{array}{l}\text { Very little can be done to help cancer patients during the last } \\
\text { weeks of life }\end{array}$ & 3.0 & 2.0 & 0.054 \\
\hline $\begin{array}{l}\text { Patients should be told the truth if they ask whether they are going } \\
\text { to die }\end{array}$ & 9.0 & 9.0 & 0.862 \\
\hline It is better if children do not attend funerals & 3.0 & 3.0 & 0.781 \\
\hline We do not need to talk to children about death and dying & 1.0 & 2.0 & 0.193 \\
\hline Children have no understanding of death & 2.0 & 2.0 & 0.871 \\
\hline $\begin{array}{l}\text { Relatives have a right to insist that doctors do not tell a patient he or } \\
\text { she has cancer }\end{array}$ & 3.0 & 2.0 & 0.390 \\
\hline $\begin{array}{l}\text { Chaplains and religious leaders have an important role in helping } \\
\text { non-religious terminally ill patients }\end{array}$ & 6.0 & 6.0 & 0.655 \\
\hline Patients should be allowed to die at home if that is their wish & 10.0 & 9.0 & 0.103 \\
\hline Hospices can be positive places & 9.0 & 9.0 & 0.441 \\
\hline Caring for terminally ill patients as doctors can be a rewarding job & 9.0 & 9.0 & 0.744 \\
\hline
\end{tabular}

Results shown are the median scores reported for both questionnaires. The Mann-Whitney $\mathrm{U}$ test was used to test for a difference between the questionnaires. 


\section{Summary points}

- Medical students at interview frequently state that they wish to enter medicine in order to cure patients, but caring for patients with chronic and life threatening illnesses will be a major role for the majority of doctors.

- Preclinical medical students have a positive view of caring for patients at the end of life.

- Older students demonstrated a more positive view of caring for patients with chronic or terminal illness.

effect of a hospice rotation found that students gained knowledge of both the principles and the philosophy of care and also exhibited more positive responses towards patients with advanced metastatic cancer after teaching. ${ }^{17}$ A further study in the USA indicated that more than $70 \%$ of students believed end of life care could be rewarding and $90 \%$ felt that the three components of the teaching had helped them to appreciate their own future roles in providing such care, following palliative care teaching. ${ }^{18}$

There are no papers in the literature that specifically explore age and sex with regard to attitudes towards caring for patients with chronic illness and palliative care. Female students are regarded as being more "nurturing" and as placing greater value on communication and getting to know patients, which may explain their more positive views in this study. Historically it has been found that female students are more likely to choose careers where they can achieve these values, for example general practice, palliative care and psychiatry, ${ }^{19}$ and these are also the qualities that many patients want regardless of their diagnosis. Medicine is attracting an increasing number of mature students and indeed the median age of students in our study was 20 years. Students entering medicine at an older age may have been exposed to different life experiences that influence their attitudes towards caring for chronically ill or dying patients. The increasing trend of older students entering medicine and the significant number of places allocated to postgraduate students may have a positive influence on the care of such patients.

Caring for patients with a chronic or terminal illness is an opportunity to use knowledge and skills as part of a team and to give patients the time and the opportunity to discuss some of their deepest fears and anxieties. Medical students at interview are often asked why they wish to enter medicine, and the answer frequently is "to cure patients". Perhaps what needs to be remembered is that cure may not always be a possibility but empathy and care will always be required, and the doctors of the future need to be aware of this. The trend of encouraging older students to enter medicine may encourage this approach.

\section{ACKNOWLEDGEMENTS}

We wish to thank Clare Gilles for her statistical support, Professor Stewart Petersen and Dr Laurence Howard for their initial comments on the paper, and the medical undergraduates for their enthusiastic participation.

\section{Authors' affiliations}

M Lloyd-Williams, Department of Primary Care, University of Liverpool Medical School, Liverpool, UK

N Dogra, Division of Child and Adolescent Psychiatry, Greenwood Institute, University of Leicester, Leicester, UK

\section{REFERENCES}

1 Hull F. Death, dying and the medical student. Med Educ 1991;25:491-6.

2 Barton M, Simons R. A survey of cancer curricula in Australian and New Zealand medical schools in 1997. Med J Aust 1999;170:225-7.

3 Barzansky B, Veloski J, Miller R, et al. Palliative care and end of life education. Acad Med 1999;74:S102-4.

4 Field D. Formal instruction about death and dying in UK medical schools. Med Educ 1984; 18:429-34.

5 Field D. Education for palliative care: formal education about death, dying and bereavement in UK medical schools in 1983 and 1994. Med Educ 1995;29:414-19.

6 McDonald N, Boisvert M, Dudgeon D, et al. The Canadian palliative care education group. J Palliat Care 2000;16:13-15.

7 Oneschuk D, Hanson J, Bruera E. An international survey of undergraduate medical education in palliative medicine. J Pain Symptom Manage 2000;20:174-9.

8 Merrill J, Lorimor R, Thornby J, et al. Caring for terminally ill persons: comparative analysis of attitudes (thanataphobia) of practising doctors, medical students and student nurses. Psychol Rep 1998;83:123-8.

9 Gates M, Kuala M, Speece M, et al. The attitudes of beginning nursing and medical students towards care of dying patients: a preliminary study. Hospice $J$ 1992;8:17-32.

10 Dionne L, Dionne A. A questionnaire to medical students on palliative care and euthanasia. J Palliat Care 1996;12:39-46.

11 Deary I, Smith R, Mitchell C, et al. Geriatric medicine: does teaching alter medical students' attitudes to elderly people? Med Educ 1993:27:399-405.

12 Elizur A, Rosenheim E. Empathy and attitudes among medical students: the effects of group exercises. J Med Educ 1982;57:675-83.

13 Furnham A. Attitudes to the medical specialities: comparing pre-clinical students' perception of nine specialities. Soc Sci Med 1986;23:587-94.

14 Lennox A, Petersen S. Development and evaluation of community based, multi-agency course for medical students: descriptive study. BMJ 1998;316:596-9.

15 Weinstein S, Laux L, Thornby J, et al. Medical students attitudes toward pain and the use of opioid analgesics. South Med J 2000;93:472-8.

16 Mason C, Fenton G. How successful is teaching on terminal care? Med Educ 1986;20:342-8.

17 Knight C, Knight P, Gellula M, et al. Training our future physicians: a hospice rotation for medical students. Am J Hospice Palliat Care 1992;8:23-8.

18 Ross D, O'Mara A, Pickens N, et al. Hospice and palliative care education in medical school. J Cancer Educ 1997;12:152-6.

19 Field D, Lennox A. Gender in medicine: the views of first and fifth year medical students. Med Educ 1996;30:246-52. 
psychologists have brought rather different frameworks. Many who work in this field apply ideas taken from studying individuals, including an emphasis on the unconscious mind. One of the commonest principles they use for understanding clinical activity is that much behaviour that appears designed to meet the needs of patients may covertly be serving darker purposes. This can include protecting clinicians from unmanageable anxiety, or enacting a concealed wish to punish others. It is relatively easy to notice this in the way that some people behave at work: you have only to think of your most controlling or bossy colleagues in order to perceive. What is harder for many people is to accept that such psychological mechanisms are present in all of us, indeed universal in the caring professions, and may even guide how whole institutions function. Yet some psychologists argue this is indeed the case.
In a classic collection of essays about how the unconscious mind affects the workplace, Anton Obholzer and Vega Zagier Roberts look at both troubled organisations and healthy ones. ${ }^{3}$ They demonstrate that places such as waiting rooms are inevitably ones where we have licence to treat patients badly, and to make up credible excuses for doing so. Unlike most sociologists, however, they also offer remedies for this. They show how clinical teams can learn to acknowledge their own destructive tendencies and bring these under conscious control. They give examples of how professionals who can do this behave more compassionately towards patients, and indeed towards each other. Teams then feel free to start changing dysfunctional systems that seemed unchallengeable, or just part of the natural order of things. If Obholzer and Roberts are right-and I believe they are-each of us can take responsibility for changing some of the things that patients most dislike, or find inexcusable in doctors. An improvement in waiting times would be a good place to start.

Contributors John Launer.

Competing interests None.

Provenance and peer review Commissioned; internally peer reviewed.

Published Online First 3 May 2012

Postgrad Med J 2012;88:361-362.

doi:10.1136/postgradmedj-2012-131048

\section{REFERENCES}

1. Foucault M. The Birth of the Clinic: An Archaeology of Medical Perception. London: Vintage Books, 1994.

2. Strong PM. The Ceremonial Order of the Clinic: Parents, Doctors and Medical Bureaucracies. London: Routledge, 1979.

3. Obholzer 0, Zagier Roberts V. The Unconscious at Work: Individual and Organizational Stress in the Human Services. London: Routledge, 1994.

\section{Retraction}

Lloyd-Williams M, Dogra N. Attitudes of preclinical medical students towards caring for chronically ill and dying patients: does palliative care teaching make a difference? Postgrad Med J 2004;80:31-4. This article has been retracted.

Postgrad Med J 2012;88:362. doi:10.1136/pgmj.2003.009571ret 